\title{
Hubungan Sikap dan Perilaku Orangtua Dalam Pemberian Minuman Menggunakan Botol Susu Terhadap Terjadinya Karies Botol Pada Siswa Tk Al-Azhar 2 Bandar Lampung
}

\author{
Avoanita Yosa, Bintang H. Simbolon \\ Jurusan Keperawatan Gigi Poltekkes Tanjungkarang
}

\begin{abstract}
Abstrak
Sikap dan perilaku orang tua sangat berpengaruh terhadap sikap dan perilaku anaknya yang tercermin pada kesehatan gigi anak. Sikap bukan hanya kondisi internal psikologis yang murni, tetapi proses kesadaran individual yang dipengaruhi oleh pengalaman pribadi, orang lain, kebudayaan dan media massa. Perilaku seseorang dipengaruhi oleh lingkungan melalui observasional learning, cara pandang, dan cara pikir yang dimiliki seseorang terhadap informasi . Orang tua merupakan model yang ditiru oleh seorang anak. Tujuan dari penelitian ini untuk mengetahui hubungan sikap dan perilaku orang tua dalam pemberian minuman menggunakan botol susu terhadap terjadinya karies botol pada siswa/i TK. Penelitian dilakukan secara potong lintang pada 71 siswa/i dan orang tua Taman Kanak-Kanak Al-Azhar 2 Bandar Lampung. Kesimpulan dari penelitian ini menunjukkan sebagian besar orang tua dari responden adanya hubungan sikap dan perilaku orang tua terhadap terjadinya karies botol pada anak. Petugas kesehatan Puskesmas sebaiknya membina dalam bidang kesehatan gigi di TK Al-Azhar 2 Bandar Lampung yang merupakan salah satu sekolah di wilayah kerja Puskesmas.
\end{abstract}

Kata kunci : orang tua, sikap, perilaku, karies botol

\section{The Relationship of Attitude And Behavior of Parents In Giving Of Drinks Using Milk Bottle Against The Caries Of Bottles At Students Kindergarten of Al-Azhar 2 Bandar Lampung}

\begin{abstract}
Parents' attitudes and behavior are crucial to attitudes and behaviors attached to children's dental health. Attitude is not only a pure internal condition, but the cognitive process of individuals, society, mass media. A person's behavior by the environment through observational learning, ways, and ways of thinking are on the way to information. Parents are models imitated by a child. The purpose of this study to determine the relationship of attitudes and behaviors of parents in drinking using bottles of milk on nursing bottle caries in students of kindergarten. The study was cross sectional on 71 students / people and parents of Kindergarten Al-Azhar 2 Bandar Lampung. The research results showed the relationship of attitude and behavior of parents in giving of drinks using milk bottle againts the caries of bottles . puskesmas health personnel are included in the dental health field at tk al-azhar 2 bandar lampung which is one of the schools in the working area of puskesmas.
\end{abstract}

Keywords : parents, attitude, nursing bottle caries

Korespondensi: drg. Avoanita Yosa, M.Kes. Jurusan Keperawatan Gigi. Politeknik Kesehatan Tanjungkarang. Jln. Soekarno-Hatta No. 1 Bandar Lampung. Mobile 085279628373.e-mail : yosaavoanita@yahoo.co.id 


\section{Pendahuluan}

Kesehatan gigi dan mulut merupakan bagian dari kesehatan tubuh yang tidak dapat dipisahkan satu sama lainnya, sebab kesehatan gigi dan mulut akan mempengaruhi kesehatan secara keseluruhan. Pada umumnya keadaan sehat terutama bidang kesehatan gigi dan mulut kondisinya masih memprihatinkan. Hasil survey Riskesdas tahun 2013 oleh Badan Litbangkes menunjukkan indeks DMF-T Indonesia sebesar 4,6 dan di Provinsi Lampung DMF-T sebesar 4,5. Hal ini lebih besar dibandingkan target WHO dimana DMF-T $\leq 3$. Sedangkan profil kesehatan Indonesia tahun 2013 menunjukkan prevalensi penduduk Indonesia yang menderita karies gigi sebesar $70 \%$, dimana diantaranya adalah golongan umur anak balita (Tantursyah, 2014).

Karies gigi anak adalah karies gigi yang sering dijumpai baik pada gigi sulung maupun gigi tetap dengan kerusakan gigi yang dimulai dari enamel berlanjut ke dentin dan menjalar ke pulpa. Proses terjadinya karies pada gigi sulung relatif lebih cepat menyebar, meluas dan lebih parah dibandingkan dengan karies pada gigi tetap (Newburn, 1978). Akibatnya gigi sulung yang terkena karies dapat mempengaruhi proses pengunyahan makanan dalam mulut sehingga pemenuhan gizi pada anak akan berkurang.

Proses tumbuh kembang anak salah satunya dengan pemeliharaan kesehatan gigi anak yang melibatkan interaksi antara anak dan orang tua, dengan kata lain masalah kesehatan gigi pada anak tidak lepas dari sikap dan perilaku orang tua terutama ibu sebagai orang yang paling dekat dengan anak. Ibu harus mengetahui cara merawat gigi anak dan mengajarkan cara merawat gigi yang baik. Walaupun masih gigi susu, seorang anak harus mendapatkan perhatian serius dari orang tua karena kondisi gigi susu akan menentukan pertumbuhan gigi permanen anak (Gultom M, 2009). Hasil penelitian tentang hubungan sikap dan perilaku orang tua dalam menjaga kesehatan gigi dan mulut anak di kecamatan Ciputat dan kecamatan Pasar Minggu Jakarta menunjukkan bahwa $84,1 \%$ ibu yang memiliki anak bawah lima tahun memiliki sikap kurang baik dan $89 \%$ memiliki perilaku yang kurang baik dalam pemeliharaan kesehatan gigi anak (Suryawati, 2014).

Salah satu sikap dan perilaku tersebut adalah penggunaan botol susu menjelang tidur yang frekuensi dan insensitas pemberiannya kurang tepat yang menyebabkan terjadinya karies gigi pada anak. Kejadian ini disebut dengan istilah Nursing Bottle Caries (Syaifuddin, 2007). Dipaparkan oleh dokter spesialis kesehatan gigi anak M Fahlevi Rizal saat mempertahankan disertasinya untuk meraih gelar doktor dengan tema "Pengaruh kebiasaan minum susu botol terhadap potensi karies gigi pada usia 3-5 tahun di Jakarta (20/6/2009)", bahwa karies botol dialami oleh sekitar $85 \%$ anak usia dibawah lima tahun. Sama halnya dari hasil penelitian di 100 taman kanak-kanak di Yogyakarta tentang karies botol ditemukan sebesar 85\% anak menderita Nursing Bottle Caries. Rumini, 2012). Selain itu penelitian yang dilakukan oleh Sondang Siregar dkk tahun 2012 di kelurahan Sei Putih Timur II Medan tentang pengaruh pola pemberian ASI dan PASI terhadap timbulnya karies botol pada anak balita menyatakan bahwa $69,9 \%$ balita menderita karies botol.

Penelitian tentang karies gigi anak perlu dilakukan agar kesehatan gigi anak terawat sedini mungkin. Hasil observasi peneliti bulan Maret tahun 2017 terhadap 150 siswa TK AlAzhar 2 Bandar Lampung diperoleh data bahwa terdapat 43 orang siswa yang menderita nursing bottle caries. Oleh karena itu dilakukan penelitian untuk mengetahui hubungan sikap dan perilaku orang tua dalam pemberian minuman menggunakan botol susu terhadap terjadinya karies botol di TK Al-Azhar 2 Bandar Lampung.

\section{Metode}

Rancangan penelitian ini adalah penelitian kuantitatif dengan metode potong cross sectional. Variabel independen terdiri dari 2 variabel yaitu: sikap orang tua dan perilaku orang tua sedangkan variabel dependen adalah terjadinya karies botol (nursing bottle caries).

Populasi adalah seluruh orang tua/wali dari siswa/i pada Taman Kanak-Kanak AlAzhar 2 Bandar Lampung. Sampel diambil dengan cara accidental sampling. Penelitian dilakukan selama kira-kira 3 bulan dari bulan Agustus sampai Oktober tahun 2017.

Teknik pengumpulan data dilakukan dengan mengambil data sikap dan perilaku orang tua dalam pemberian minuman manis atau susu melalui botol susu pada anak, ini merupakan data primer. Data primer lainnya yang diambil adalah data tentang siswa/i yang mengalami nursing bottle caries. Data ini diambil dengan cara mewawancarai orang tua dengan lembar kuesioner. Sedangkan data sekunder yang diambil pada penelitian ini 
adalah data tentang identitas siswa/i, identitas orang tua/ wali murid, juga data tentang TK termasuk data tentang UKGS.

Instrumen pada penelitian ini adalah: alat-alat diagnostik, bahan-bahan diagnostik, lembar kuesioner, alat tulis dan lembar pemeriksaan gigi.

Teknik pengumpulan data adalah dengan melakukan pengisian kuesioner pada orang tua siswa/i yang meliputi: melakukan uji reabilitas dan uji validitas instrument di TK Al Azhar 2, membuat ethical clearance untuk mendapatkan surat izin penelitian, membuat kontrak waktu dengan kepala sekolah untuk jadwal pemeriksaan gigi dan jadwal mengundang orang tua murid, melakukan informed consent dan pemberian lembar kuesioner untuk diisi oleh orang tua siswa/i dan identifikasi subyek penelitian.

Analisis data dilakukan dengan 2 tahap, yaitu, analisa univariat dilakukan untuk mendapatkan gambaran distribusi frekuensi dari variabel sikap, perilaku orang tua dan tingkat keparahan karies botol pada siswa/i TK. Analisis bivariat dilakukan untuk mengetahui hubungan sikap dan perilaku orang tua dalam pemberian minuman menggunakan botol susu terhadap terjadinya karies botol pada siswa/i TK dengan memakai uji chi square.

\section{Hasil}

Tabel 1. Distribusi Frekuensi Sikap Orang Tua

\begin{tabular}{lcc}
\hline \multicolumn{1}{c}{$\begin{array}{c}\text { Variabel } \\
\text { Sikap }\end{array}$} & Frekuensi & Persentase \\
\hline Negatif & 33 & 46,5 \\
Positif & 38 & 53,5 \\
\hline Total & 71 & 100,0 \\
\hline
\end{tabular}

Dari seluruh sampel pada penelitian ini diperoleh data sikap orang tua terhadap terjadinya karies botol pada anak yang mempunyai kriteria bersikap negative berjumlah 33 orang (46,5\%), sedangkan yang mempunyai kriteria bersikap positif berjumlah 38 orang $(53,5 \%)$. Didapatkan lebih banyak orang tua yang bersikap positif dibandingkan dengan orang tua yang bersikap negatif.

Distribusi frekuensi perilaku orang tua dapat dilihat pada tabel berikut ini.
Tabel 2. Distribusi Frekuensi Perilaku Orang Tua

\begin{tabular}{lcc}
\hline $\begin{array}{l}\text { Variabel } \\
\text { Perilaku }\end{array}$ & Frekuensi & Persentase \\
\hline Negatif & 34 & 47,9 \\
Positif & 37 & 52,1 \\
\hline Total & 71 & 100,0 \\
\hline
\end{tabular}

Pada hasil penelitian ini diperoleh keterangan bahwa perilaku orang tua terhadap terjadinya karies botol pada anak yang mempunyai kriteria berperilaku negatif berjumlah 34 orang (47,9\%), sedangkan yang mempunyai kriteria bersikap positif berjumlah 37 orang $(52,1 \%)$.

Tabel 3. Distribusi Frekuensi Karies Botol Pada Anak

\begin{tabular}{lcc}
\hline \multicolumn{1}{c}{$\begin{array}{c}\text { Variabel } \\
\text { Karies Botol }\end{array}$} & Frekuensi & Persentase \\
\hline Parah & 53 & 74,6 \\
Tidak Parah & 18 & 25,4 \\
\hline Total & 71 & 100,0 \\
\hline
\end{tabular}

Pada penelitian ini diperoleh data karies botol pada anak yang mempunyai kriteria parah berjumlah 53 orang $(74,6 \%)$, sedangkan yang mempunyai kriteria tidak parah berjumlah 18 orang $(25,4 \%)$.

Analisa bivariat dilakukan untuk mengetahui hubungan antara variabel independen /bebas yaitu sikap dan perilaku orang tua dengan variabel terikat yaitu karies botol pada siswa/i TK Al-Azhar 2 Bandar Lampung, analisa bivariat yang digunakan dengan uji Chi Square.

Tabel 4. Hubungan Antara Sikap dan Perilaku Orang Tua Terhadap Karies Botol Pada Siswa/i

\begin{tabular}{|c|c|c|c|c|c|c|}
\hline \multirow{3}{*}{ No } & \multirow{3}{*}{ Variabel } & \multicolumn{4}{|c|}{$\begin{array}{c}\text { Karies } \\
\text { Karies Botol }\end{array}$} & \multirow{3}{*}{$p$ value } \\
\hline & & \multicolumn{2}{|c|}{ Parah } & \multicolumn{2}{|c|}{$\begin{array}{l}\text { Tidak } \\
\text { Parah }\end{array}$} & \\
\hline & & $\mathrm{n}$ & $\%$ & $\mathrm{~N}$ & $\%$ & \\
\hline 1 & $\begin{array}{l}\text { Sikap: } \\
\text { - Negatif } \\
\text { - Positif }\end{array}$ & $\begin{array}{l}29 \\
24\end{array}$ & $\begin{array}{l}87,9 \\
63,2\end{array}$ & $\begin{array}{l}4 \\
14\end{array}$ & $\begin{array}{l}12,1 \\
36,8\end{array}$ & 0,034 \\
\hline 2 & $\begin{array}{l}\text { Perilaku: } \\
\text { - Negatif } \\
\text { - Positif }\end{array}$ & $\begin{array}{l}33 \\
20\end{array}$ & $\begin{array}{l}97,1 \\
54,1\end{array}$ & $\begin{array}{l}1 \\
17\end{array}$ & $\begin{array}{l}2,9 \\
45,9\end{array}$ & 0,000 \\
\hline
\end{tabular}


Data pada tabel 4 menunjukkan bahwa hasil uji statistik sikap orang tua terhadap karies botol pada anak, didapatkan nilai $\mathrm{p}=$ $0,034(\mathrm{p}<0,05)$, sehingga disimpulkan bahwa ada hubungan yang signifikan antara sikap orang tua terhadap karies botol pada anak. Sedangkan perilaku orang tua terhadap karies botol pada anak, didapatkan nilai $\mathrm{p}=0,000(\mathrm{p}<$ $0,05)$, sehingga disimpulkan ada hubungan yang signifikan antara perilaku orang tua terhadap karies botol pada anak.

\section{Pembahasan}

Pada penelitian ini diperoleh kesimpulan bahwa sikap orang tua mempunyai hubungan yang signifikan dengan terjadinya karies botol pada siswa/i TK Al-Azhar 2 Bandar Lampung. Hal ini sejalan dengan penelitian Adlina Fildzah yang menyatakan bahwa sikap orang tua tentang kesehatan gigi dan mulut mempunyai hubungan dengan kejadian karies gigi anak pada usia 3 - 5 tahun di BA Melati Kecamatan Candiroto Kabupaten Temanggung tahun 2015.

Menurut Notoatmodjo (2007) sikap merupakan reaksi atau respon seseorang yang masih tertutup terhadap suatu objek, sedangkan perilaku merupakan kumpulan dari berbagai faktor yang saling berinteraksi. Tetapi sering tanpa disadari bahwa interaksi itu sangat kompleks sehingga kadang tidak sempat memikirkan penyebab seseorang menerapkan perilaku tertentu.

Sikap adalah predisposisi untuk melakukan atau tidak melakukan suatu perilaku tertentu, sehingga sikap bukan hanya kondisi internal psikologis yang murni tetapi proses kesadaran yang sifatnya individual yang dipengaruhi oleh pengalaman pribadi, orang lain, kebudayaan dan massa media (Wawan dan Dewi, 2010).

Pada penelitian ini diperoleh data orang tua memiliki sikap negatif $46,5 \%$. Dilihat dari prosentasinya tidak begitu banyak selisih antara sikap negatif dan sikap positif orang tua, tetapi bila ditinjau dari jawaban perilaku orang tua pada nomor 4 (tidak perlu dilakukan pencegahan lubang gigi pada anak, jawaban setuju paling banyak yaitu $43,7 \%$ ). Dan dilihat dari jawaban orang tua pada nomor 5 (pemberian susu/minuman manis menggunakan botol pada anak secara terus menerus tidak akan menyebabkan karies pada anak, jawaban setuju paling banyak 64,8\%) serta jawaban nomor 9 (membiasakan anak meminum susu / minuman manis sebelum tidur tidak akan mempengaruhi terjadinya karies botol, jawaban setuju paling banyak yaitu $42,3 \%$ ). Hal ini menunjukkan bahwa sikap orang tua yang negatif dapat menyebabkan terjadinya karies botol pada anak. Sikap dipengaruhi oleh pengetahuan seseorang. Oleh karena itu, perlu merubah sikap orang tua dengan melakukan penyuluhan kesehatan gigi dan mulut terutama karies botol terhadap orang tua murid TK, oleh petugas kesehatan dari Puskesmas yang bekerjasama dengan TK AlAzhar 2 setiap tahunnya.

Orang tua memiliki sikap, menurut Meinarly Gultom (2009) juga mengemukakan bahwa sikap dan perilaku orang tua memiliki hubungan yang signifikan dalam pemeliharaan kesehatan giginya. Apabila sikap dan perilaku orang tua baik dalam menjaga kesehatan gigi maka kesehatan gigi dan mulut anaknya juga dapat terjaga dengan baik, begitu pula sebaliknya apabila sikap dan perilaku orang tua buruk maka kesehatan gigi dan mulut anaknya juga akan terganggu. Disamping itu belum pernahnya TK Al-Azhar 2 Bandar Lampung ini mendapatkan penyuluhan tentang karies botol, seperti dari petugas Puskesmas yang mempunyai wilayah mencakup TK Al-Azhar 2 tersebut, juga tidak tersedianya fasilitas pelayanan kesehatan seperti UKGS juga dapat menjadi factor penyebab karies botol pada anak.

Menurut Meinarly Gultom sikap dan perilaku orang tua yang buruk tentang kesehatan gigi dan mulut akan mempengaruhi perubahan kesehatan gigi dan mulut anak khususnya sikap dan perilaku orang tua dalam pemberian susu botol dengan frekuensi dan intensitas pemberiannya yang kurang tepat.

Pemeliharaan kesehatan gigi dan mulut anak melibatkan interaksi langsung anak dan orang tua karena kesehatan gigi anak tidak lepas dari sikap dan perilaku orang tua sebagai orang yang paling dekat dengan anak. Dengan kata lain orang tua harus mengetahui cara memelihara atau merawat gigi anaknya dan mengajarkan anaknya cara merawat gigi yang baik dan benar agar terhindar dari karies botol.

Penyebab utama terjadinya karies dipicu oleh pemberian larutan yang manis seperti air susu atau minuman manis menggunakan botol, lamanya larutan tersebut berada di rongga mulut sampai ketika anak tertidur sambil mengemut (mengedot) air susu dalam botol lebih memperparah terjadinya karies. Gigi susu lebih mudah terserang karies daripada gigi tetap, disebabkan karena enamel gigi susu lebih banyak mengandung bahan organik dan air, 
sedangkan jumlah mineral lebih sedikit dibandingkan gigi tetap. Bakteri menggunakan gula sebagai makanan utamanya, kemudian memproduksi asam yang akan merusak gigi, asam menyerang gigi sekitar 20 menit atau lebih. Meminum susu / minuman mengandung gula menggunakan botol ketika tertidur sangat tidak baik, cairannya akan menggenangi rongga mulut (gigi) untuk beberapa waktu (jam). Sahip Syarifi (2008) mengemukakan bahwa pada genangan susu saat tidur, ditemukan terjadinya fermentasi yang berasal dari gula larutan tersebut dan akan membantu terjadinya karies.

Perilaku adalah apa yang dikerjakan oleh organisme bersangkutan, baik dapat diamati secara langsung atau secara tidak langsung. (Wawan, 2010). Penelitian ini menunjukkan adanya hubungan antara perilaku orang tua terhadap terjadinya karies pada anak. Hal ini sejalan dengan hasil penelitian Andriyani Mustika N (2014) ada hubungan signifikan antara perilaku perawatan gigi anak dengan kejadian karies gigi di TK Taman Indria. Perilaku diartikan sebagai suatu aksi atau reaksi manusia (organisme) terhadap lingkungannya.

Bandura (1971) dalam teori pembelajaran sosial menyatakan bahwa perilaku sesorang dipengaruhi oleh lingkungan melalui observasional learning, cara pandang dan cara pikir yang dimiliki seseorang terhadap informasi. Didalam suatu pembentukan dan atau perubahan, perilaku dipengaruhi oleh beberapa faktor yang berasal dari dalam dan luar individu itu sendiri. Saparinah Sadli (1982) di dalam Wawan (2010) mengatakan perilaku kesehatan individu dan kebiasaan individu erat kaitannya dengan lingkungan seperti lingkungan keluarga, kebiasaan-kebiasaan tiap anggota keluarga mengenai kesehatan. Orang tua terutama ibu sangat mempengaruhi perilaku seorang anak. Apabila orang tua tidak mempunyai perilaku pemeliharaan kesehatan yang baik dapat mempengaruhi kesehatan anak. Dapat dicontohkan orang tua membiarkan anak tertidur dengan tetap meminum susu / minuman manis melalui botol susu karena takut anaknya akan terbangun bila diambil botol susunya.

Perilaku ini bila dibiarkan terus dapat mengganggu kesehatan gigi si anak dan menyebabkan terjadinya karies botol pada gigi si anak. Seorang guru sebenarnya dapat mempengaruhi perubahan perilaku anak. Guru dapat mengajarkan anak (siswa TK) untuk merubah kebiasaan perilaku si anak meminum susu / minuman manis melalui susu botol sampai tertidur. Karena menurut Bandura (1971) dalam Hasan M (2011) perilaku seseorang juga dapat mempengaruhi lingkungan sekitar dan menciptakan penguat dan observational opportunity yang kemungkinan bias diamati oleh orang lain.

Simpulan dalam penelitian ini yaitu didapatkan 1) Distribusi frekuensi sikap orang tua dalam pemberian minuman menggunakan botol susu terhadap terjadinya karies botol didapat yang bersikap negative sebesar $46,5 \%$ dan yang bersikap positif sebesar 53,5\%. 2) Distribusi frekuensi perilaku orang tua dalam pemberian minuman menggunakan botol susu terhadap terjadinya karies botol didapat yang berperilaku negative sebesar 25,4\%. 3) Distribusi frekuensi terjadinya karies botol yang parah sebesar $74,6 \%$ dan yang tidak parah sebesar 34\%. 4) Variabel sikap orang tua mempunyai hubungan yang signifikan terhadap terjadinya karies botol pada anak TK Al-Azhar 2 Bandar Lampung, dimana $\mathrm{p}=0,034$. 5) Variabel perilaku orang tua mempunyai hubungan yang signifikan terhadap terjadinya karies botol pada anak TK Al-Azhar 2 Bandar Lampung dimana $p=0,000$

Saran yang dapat diberikan bagi institusi untuk dapat mengadakan sarana praktik Pendidikan Kesehatan Gigi terutama tentang karies botol bagi mahasiswa Keperawatan Gigi di Taman Kanak-Kanak di kota Bandar Lampung, dan bagi lahan penelitian untuk dapat bekerjasama dengan pihak Puskesmas melalui pengadaan penyuluhan pada orang tua dalam merubah sikap dan perilaku orang tua dan siswa/i TK Al-Azhar 2 agar mencegah terjadinya karies botol pada anak.

\section{Daftar Pustaka}

1. Kementerian Kesehatan RI,2013. Riset Kesehatan Dasar 2013.

2. Tantursyah, 2014. Pendidikan Kesehatan Gigi di Sekolah, Raja Grafindo Persada, Jakarta.

3. Gultom Meinarly, 2009. Pengetahuan, Sikap dan Tindakan Ibu Rumah Tangga Terhadap Pemeliharaan Kesehatan Gigi dan Mulut Anak Balitanya di Kecamatan Balige Kabupaten Toba Samosir, tersedia (http://repository.usu.ac.id/MeinarlyGulto $\mathrm{m} /$ )

4. Suryawati, 2014. Hubungan Sikap dan Perilaku Orang Tua Dalam Menjaga Kesehatan Gigi dan Mulut Anak di 
Kecamatan Ciputat dan Kecamatan Pasar Minggu, Jakarta.

5. Syaifuddin, 2007 , Karies pada anak ,Muha Medika, Yogyakarta

6. Syarifi, 2008 ,Minum susu menggunakan botol menyebabkan karies parah pada anak, Grahadi ,Yogyakarta

7. Newburn, 1978 ,Cariology. Baltimore : William \& Wilkins

8. Rizal M Fahlevi, 2009. Pengaruh Kebiasaan Minum Susu Botol Terhadap Potensi Karies Gigi Pada Anak Usia 3-5 Tahun, Disertasi Doktor, Universitas Indonesia, Jakarta.

9. Rumini, 2012. Peranan Orang Tua dan Perilaku Anak Dalam Menyikat Gigi Dengan Kejadian Karies Botol Anak, Yogyakarta.

10. Wawan ; Dewi M, 2010. Teori dan Pengukuran Pengetahuan, Sikap dan Perilaku Manusia, Nuha Medika, Yogyakarta.

11. Adlina Fildzah Maharani, 2015. Hubungan Pengetahuan, Sikap dan Perilaku Orang Tua Tentang Kesehatan Gigi dan Mulut Dengan Kejadian Karies Gigi Anak, Thesis FKG Universitas Islam Sultan Agung (Unissula) Semarang.

12. Notoatmodjo Soekidjo, 2007. Promosi Kesehatan dan Ilmu Perilaku, Rineka Cipta, Jakarta.

13. Andriyani Mustika N, dkk, (2015). Perilaku Ibu Dalam Perawatan Gigi Anak Dengan Kejadian Karies Gigi Anak Usia Pra Sekolah, Jurnal Keperawatan Volume 7 No 2, September 2015.

14. Hasan Mustafa, Perilaku Manusia Dalam Perspektif Psikologi Sosial, Jurusan Ilmu Administrasi Bisnis, Fakultas Ilmu Sosial dan Ilmu Politik Universitas Katolik Parahyangan (Jurnal Administrasi Bisnis, 2011), Vol 7 No 2 